\title{
Prognostic values of long noncoding RNA PVT1 in various carcinomas: An updated systematic review and meta-analysis
}

\author{
Meizhu Xiao | Ying Feng | Chongdong Liu | Zhenyu Zhang
}

Department of Obstetrics and Gynecology, Beijing Chaoyang Hospital, Capital Medical University, Beijing, China

Correspondence: Zhenyu Zhang, Department of Obstetrics and Gynecology, Beijing Chaoyang Hospital, Capital Medical University, No. 8 Gongti Nan Road, Chaoyang District, Beijing 100020, China (zhenyuzhang2000@163.com).

Funding information

Ministry of Science and Technology of China, Grant/Award Number: 2012DFA30490 and 2017YFC1001204

\begin{abstract}
Cancers have been a worldwide health problem with a high mortality rate, but ideal biomarkers are not available to effectively screen and diagnose patients. Currently, an increasing number of long noncoding RNAs have been reported to be abnormally expressed in human carcinomas and play a vital role in tumourigenesis. Plasmacytoma variant translocation 1 (PVT1) is upregulated in various carcinomas, and its overexpression is associated with poor survival in cancer patients. We conduct an updated meta-analysis to determine its potential in prognosis for tumours. In total, 14 studies comprising 2435 patients were enrolled according to Reporting Recommendations for Tumour Marker Prognostic Studies guidelines. High PVT1 expression indicated poor overall survival (hazard ratio $[\mathrm{HR}]=1.98,95 \%$ confidence interval $[\mathrm{Cl}]: 1.62-2.42$, $P<0.00001)$ and disease-free survival $(H R=1.63,95 \% \mathrm{Cl}: 1.45-1.84, P<0.00001)$. Additionally, increased PVT1 expression was positively associated with lymphatic node metastasis (odd ratio $[\mathrm{OR}]=2.87,95 \% \mathrm{Cl}: 1.66-4.96, P=0.0002$ ), distant metastasis (OR $=2.47,95 \% \mathrm{Cl}: 1.74-3.50, P<0.00001)$, advanced tumour-node-metastasis stages $(\mathrm{OR}=2.59,95 \% \mathrm{Cl}: 1.38-4.88, P=0.003)$. New findings highlight that PVT1 acts as competing RNA to microRNAs to protect mRNAs from miRNAs repression. Therefore, we also discuss PVT1-related microRNAs and their interaction in tumourigenesis. In conclusion, PVT1 may be a potential biomarker of poor prognosis for patients with different cancer types.
\end{abstract}

\section{1 | INTRODUCTION}

Cancer has been a major health problem worldwide. The World Health Organization estimated that approximately 14.1 million new cancer patients and 8.2 million deaths occurred in 2012, and greater than 20 million new patients with malignant tumour will be diagnosed as early as $2015 .{ }^{1}$ At present, cancer patients, especially those with high-risk features, such as lymph node metastasis (LNM), distant metastasis (DM), or late-stage tumours, exhibit a high mortality rate and a poor 5-year survival rate. Currently, no ideal biomarkers are available to screen or diagnose cancer effectively. Therefore, the identification of a new biological target that plays a guiding role in carcinogenesis is urgently needed to detect cancer and predict survival.

Long noncoding RNAs (IncRNAs) are referred to RNAs longer than 200 nucleotides and lack of protein-coding capacity given the absence of open-reading frames. ${ }^{2}$ Recent reports suggest that IncRNAs play a vital role in carcinogenesis and the development of cancers. ${ }^{3}$ With the application of high-throughput RNA sequencing techniques, abundant IncRNAs were identified. ${ }^{4}$ Accumulating evidence demonstrates that IncRNAs play multiple and critical roles in the initiation and progression of various cancers and noncancerous diseases. $^{5-8}$

The human PVT1 gene, which is homologous to the mouse plasmacytoma variant translocation gene 1 , was originally defined as a cluster of chromosomal translocation or viral integration breakpoints and is a long intergenic noncoding RNA (lincRNA). ${ }^{9}$ The human PVT1 lies in human band 4 of region 2 on the long arm of chromosome 8 (8q24). This locus is a recognized cancer risk locus with the top target of copy number alterations and is also located near the well-known avian myelocytomatosis viral oncogene homolog (MYC) oncogene. ${ }^{10}$ Moreover, the PVT1 locus 
gives rise to several alternatively spliced noncoding transcripts, ${ }^{11}$ and PVT1 is the host to a cluster of microRNAs (miRNAs), including miR-1204, miR-1205, miR-1206, miR-1207-5p, miR-1207-3p, and miR-1208. ${ }^{12}$ Recent evidence indicates that PVT1 is dysregulated in various human carcinomas, including gastric cancer (GC), ${ }^{5,8,13-16}$ lung cancer, ${ }^{6,17-22}$ colorectal cancer (CRC), ${ }^{23}$ oesophageal cancer, ${ }^{24}$ pancreatic cancer (PC), ${ }^{25-27}$ hepatocellular carcinoma (HCC), ${ }^{28-30}$ breast cancer, ${ }^{31}$ cervical cancer (CC), ${ }^{32,33}$ head and neck squamous cell carcinoma (HNSCC), ${ }^{34}$ ovarian cancer (OC), ${ }^{35}$ osteosarcoma, ${ }^{1}$, melanoma, ${ }^{38}$ and noncancerous diseases. ${ }^{7,8}$ Furthermore, PVT1 overexpression is associated with clinicopathological characteristics in various cancers with high levels of PVT1 indicating poor overall survival (OS), disease-free survival (DFS), and/or progression-free survival (PFS). ${ }^{5,6}$ PVT1 contributes to tumour cell proliferation, migration, and invasion in various cancer cells via various mechanisms. Wu et $\mathrm{al}^{25}$ revealed that PVT1 could transcriptionally downregulate p21 and increase zinc finger E-box-binding protein 1 (ZEB1) and Snail expression, thus promoting cell migration and proliferation in PC. PVT1 is negatively correlated with p15 and p21 expression. PVT1 overexpression promotes cell proliferation and increases the number of S-phase cells in nonsmall cell lung cancer (NSCLC). ${ }^{17}$ In addition, overexpression of PVT1 was found both in tissues and cells of cisplatin-resistant GC patients and potentially improves the expression of MDR-related genes, such as multidrug resistance 1 (MDR1), mammalian target of rapamycin, MDR-associated protein 1 (MRP1) and hypoxia-inducible factor-1 alpha (HIF-1 $\alpha$ ), in cisplatin-resistant GC cells. ${ }^{8}$ Multidrug resistance (MDR) is one of the major reasons for therapeutic failure in human cancers, which leads to recurrence, metastasis, and poor survival for cancer patients. Hence, an increasing focus is given to the clinical application of PVT1 as a potential biomarker and therapeutic target in diverse cancers.

Circular RNAs (circRNAs) have recently emerged as a new class of endogenous RNAs that form a covalently closed continuous loop with neither $5^{\prime}$-caps nor 3 '-tails and exist extensively in mammalian cells. ${ }^{38,39}$ Evolving evidence suggests that many circRNAs are closely associated with human diseases, especially cancers. ${ }^{40-43}$ Several studies have indicated that circle-PVT1 (circPVT1) was overexpressed in human HNSCC, ${ }^{34} \mathrm{GC},{ }^{15}$ and acute myeloid leukaemia. ${ }^{44}$ However, its function in human cancers remains largely unknown and even contradictory.

In this review, we will discuss the current state of PVT1, including circPVT1 in cancers, with particular emphasis on their potential clinical significance in cancer prognosis assessment and possible mechanism in carcinogenesis and tumour progression.

\section{2 | MATERIALS AND METHODS}

\section{1 | Publication search strategy}

We searched various databases, including PubMed, Web of Science, Cochrane Library, China National Knowledge Infrastructure (CNKI), and Wanfang for eligible studies published up to 1 February 2018. The following keywords were used for the searches: "plasmacytoma variant translocation 1 or PVT1" AND "cancer or tumour or carcinomas or neoplasm." Furthermore, the references in these eligible articles were also manually reviewed to identify potentially relevant studies.

\begin{tabular}{|c|c|}
\hline Checklists & Criteria \\
\hline 1. Samples & $\begin{array}{l}\text { Retrospective or prospective cohort design with a well-defined study } \\
\text { population Medical treatment applied to the patients was explained; and } \\
\text { authors have explained if all patients have received the same treatment } \\
\text { or no }\end{array}$ \\
\hline $\begin{array}{l}\text { 2. Clinical data of } \\
\text { the cohort }\end{array}$ & The basic clinical data such as age and gender were provided \\
\hline 3. qRT-PCR & $\begin{array}{l}\text { Clearly described primers, quantitation methods or referred to original } \\
\text { paper }\end{array}$ \\
\hline $\begin{array}{l}\text { 4. Specimen } \\
\text { characteristics }\end{array}$ & Primary resected tumour specimens and adjacent normal tissues \\
\hline $\begin{array}{l}5 . \\
\text { Prognostication }\end{array}$ & $\begin{array}{l}\text { The analysed survival endpoints were defined (eg, overall survival, } \\
\text { disease-free survival) }\end{array}$ \\
\hline 6. Statistics & $\begin{array}{l}\text { Cut-off point, used to divide the cases into risk groups, was well described } \\
\text { Estimated effect (HR, CI) describing the relationship between the } \\
\text { evaluated PVT1 and the outcome (overall survival, disease-free survival, } \\
\text { or progression-free survival) was provided Adequate statistical analysis } \\
\text { (eg, Cox regression modelling) was performed to adjust the estimation of } \\
\text { the effect of PVT1 for known prognostic factors }\end{array}$ \\
\hline
\end{tabular}

REMARK: reporting recommendations for tumour marker prognostic studies; PVT1: plasmacytoma variant translocation 1; qRT-PCR: quantitative real-time reverse transcription polymerase chain reaction; HR: hazard ratio; $\mathrm{Cl}$ : confidence interval.
TABLE 1 Evaluation criteria used to assess the quality of studies included in the meta-analysis of PVT1 (adapted from REMARK guidelines) 


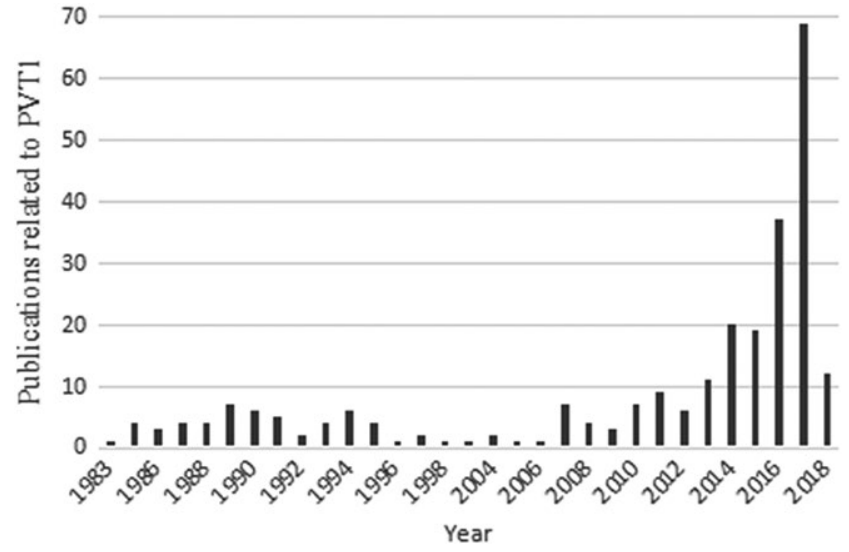

FIGURE 1 The number of publications related to PVT1

\section{2 | Inclusion and exclusion criteria}

Two investigators independently assessed and extracted data from all eligible studies. The Reporting Recommendations for Tumour Marker Prognostic Studies (REMARK) guidelines ${ }^{45,46}$ were used to evaluate the quality of studies, and the selected guidelines taken from the REMARK criteria are summarized in Table 1, based on which the inclusion criteria were listed as follows: (a) the level of PVT1 expression was examined in human cancerous tissues and adjacent noncancerous or corresponding normal tissues; (b) the method of detecting PVT1 expression was quantitative real-time reverse transcription polymerase chain reaction; (c) patients were divided into high and low expression groups according to the cutoff value of PVT1 expression; (d) associations between PVT1 expression and prognosis or clinicopathological characteristics were described; (e) estimated hazard ratios (HRs) and 95\% confidence interval $(95 \% \mathrm{Cl})$ for OS, DFS, or PFS were reported in the studies; and ( $f$ ) the studies were published in English or Chinese. All these studies would be excluded if they met any one of the following criteria: (a) not defining the high or low expression of PVT1; (b) not reporting HRs and $95 \% \mathrm{Cl}$ for OS, DFS, or PFS; (c) reviews, case reports, letters, expert opinions, editorials, meta-analyses, and conference reports; (d) exclusively focused on the molecular structure and functions of PVT1; (e) published in non-English or non-Chinese language; (f) non-human studies; and (g) duplicate publications.

\section{3 | Data extraction and quality control}

According to the inclusion and exclusion criteria, two investigators (XMZ, FY) independently extracted data from the eligible studies, and disagreements were discussed and resolved through consensus with two additional reviewers (LCD, ZZY). The following information was carefully extracted: first author name, publication year, cancer type, total patient number, detection method for PVT1 expression, number of patients in high and low PVT1 expression groups, number of patients with LNM, DM, tumour-node-metastasis (TNM) stage, lymphatic invasion, vascular invasion, invasion depth in high and low PVT1 expression groups, survival analysis method, cut-off value to define the high and low PVT1 expression, HRs and corresponding $95 \% \mathrm{Cls}$ for OS, DFS, and PFS. If the data were analysed by both univariate and multivariate methods, the latter was preferred.

\section{4 | Statistical analysis}

All extracted data analyses were performed with Review Manager version 5.2 (Revman, The Cochrane Collaboration, Oxford, UK). All the definition of DFS and PFS in the studies are very similar; thus, we integrated DFS with PFS. Then, HRs with corresponding $95 \% \mathrm{Cls}$ were applied to assess the association between PVT1 and clinical prognoses, including OS and DFS. Regarding clinicopathological factors, we divided patients into male and female groups based on gender and positive and negative groups based on whether patients were diagnosed with LNM, DM, lymphatic invasion, and vascular invasion, separately. The TNM staging system refers to the tumour $(T)$, the extent of spread to the lymph nodes (N), and the presence of metastasis (M) based on American Joint Committee on Cancer classification. In this paper, patients are divided into early-stage (I+II) group and advanced-stage (III+IV) group according to TNM stage. Similarly, we divided patients into T1-T2 and T3-T4 groups according to the tumour invasion depth. Cochrane Q-test and Higgins I $^{2}$ statistics were used to determine the heterogeneity among the included studies. If heterogeneity was present $\left(P \leq 0.05\right.$ or $\left.\mathrm{I}^{2} \geq 50 \%\right)$, then a random-effect model was applied for the analysis. Otherwise, the fixed-effect model was more appropriate. ${ }^{45}$ Subgroup and sensitivity analyses were performed to analyse the sources of heterogeneity. ${ }^{47}$ The agreement among authors (XMZ, FY) who performed the screening was evaluated using Cohen's kappa coefficient. $^{48}$

\section{3 | RESULTS}

\subsection{The studies included in this meta-analysis}

By searching various databases, including PubMed, Web of Science, Cochrane Library, CNKI, and Wanfang (up to 1 February 2018), a total of 326 studies were retrieved. Since the first literature associated with PVT1 was published in 1983, people have been paying more attention to PVT1 as demonstrated in Figure 1. Among the 326 studies, 63 duplicate or irrelevant studies were excluded. After screening titles and abstracts, 217 articles were excluded because they were reviews, meta-analysis, letters, case reports, expert opinions, or animal studies. Then, 46 potentially relevant articles were selected for full-text review. Fourteen articles with unavailable survival endpoints, 13 articles only with Kaplan-Meier survival curves but without $\mathrm{HRs}$ and $95 \% \mathrm{Cl}$, and another five articles defining the high or low PVT1 expression with Youden's Index or no information for the definition were all excluded. Authors (XMZ, FY) reached a Kappa agreement of 0.85 


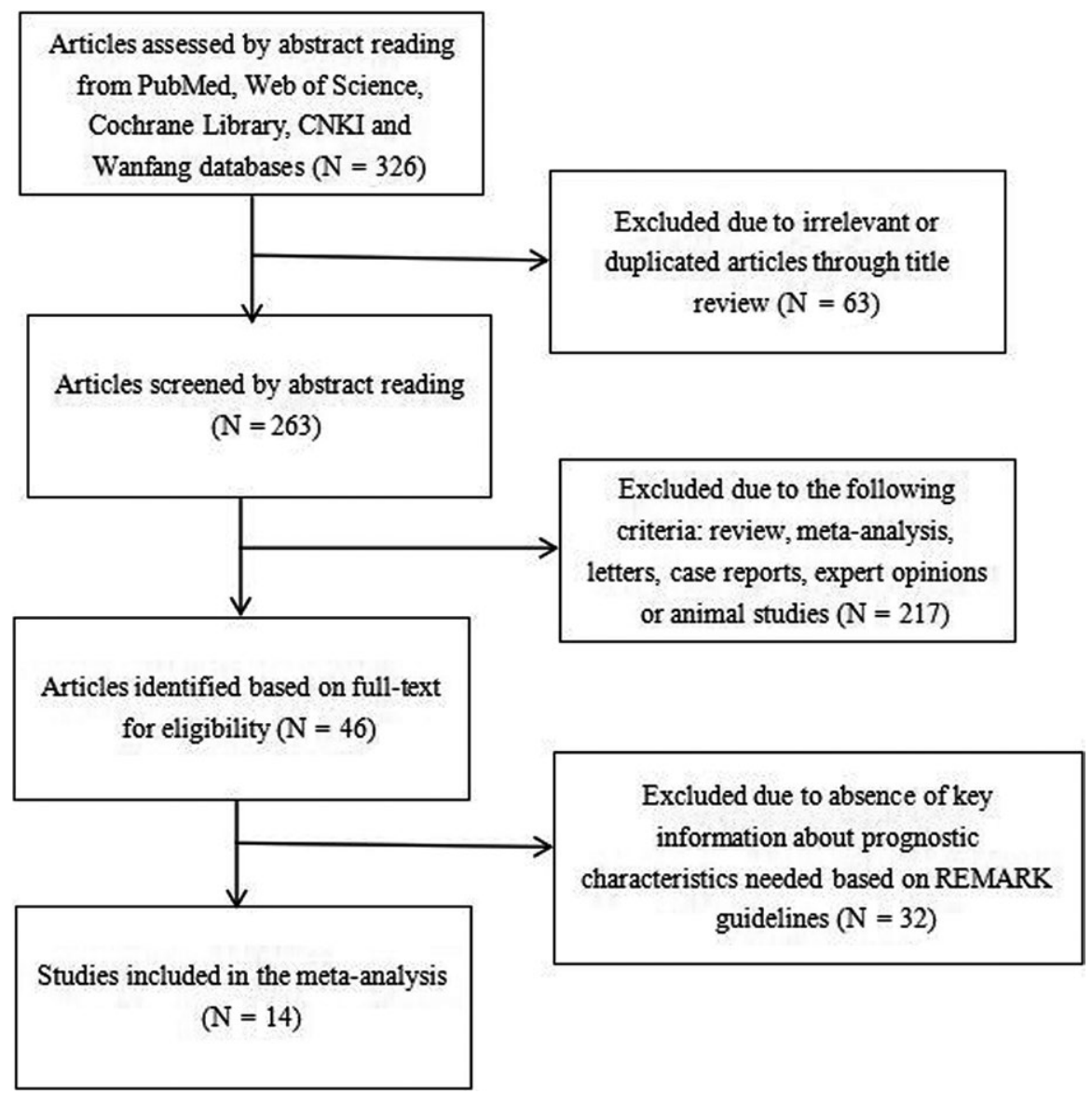

FIGURE 2 Flow chart of searching and selecting the studies

when quantifying the studies. Finally, 14 studies comprising 2435 patients were considered eligible based on the inclusion and exclusion criteria (Figure 2). These studies had an accrual period between 2014 and 2018 and sample sizes ranging from 73 to 528 (mean, 147). The studies were performed in three countries (12 from China, 1 from Japan, and 1 from India).

The basic characteristics of the included studies, of which two studies included two sets of patients and two studies analysed the association between circPVT1 and prognosis of patients, are summarized in Table 2. These included studies with clinical characteristics, such as gender, TNM stage, LNM, DM, invasion depth, vascular invasion, and lymphatic invasion in high-expression and low-expression PVT1, are presented in Table 3. Among these 14 studies, eight different cancer types were evaluated in this metaanalysis: seven studies on digestive system carcinomas, including one oesophageal squamous cell carcinomas, ${ }^{24}$ four GCs, ${ }^{13-15,49}$ one $\mathrm{CRCs},{ }^{50}$ and one $\mathrm{PCs}^{27}$; two on urogenital system carcinoma, including one $\mathrm{OC}^{35}$ and one clear cell renal cell carcinoma $(\mathrm{cCRCC})^{51}$; four on respiratory system carcinomas, including three NSCLCs $s^{17,19,20}$ and one small cell lung cancer (SCLC) ${ }^{18}$; and other systems, including one HNSCC. ${ }^{34}$ Cut-off value for high or low PVT1 expression was defined by either mean, median, or percentile value. No patient received chemotherapy or radiotherapy before surgery, and all the diagnoses of clinical characteristics were based on histopathology.

\subsection{Association between PVT1 and OS in cancers}

Pooled HRs for OS were all extracted directly from 13 studies. Twelve studies with a total of 1876 patients reported an association between PVT1 expression and OS; the pooled HR was 1.98 (95\% $\mathrm{Cl}$ : 1.62-2.42, $\mathrm{P}<0.00001$ ), indicating that PVT1 overexpression predicted poor OS for patients with these carcinomas. The random-effect model was adopted because of significant heterogeneity $\left(I^{2}=53 \%, P=0.01\right)$ (Figure $3 A$ ). As shown in Table 4, subgroup analyses were conducted based on various cancer types, cut-off values, and sample sizes. The stratified analysis by various cancer types indicated a significant association between increased PVT1 expression and poor OS in patients with digestive system carcinomas $(\mathrm{HR}=2.13,95 \% \mathrm{Cl}: 1.57-2.89, \mathrm{P}<0.00001)$, respiratory system carcinomas $(\mathrm{HR}=2.34,95 \% \mathrm{Cl}: 1.64-3.34, \mathrm{P}<0.00001)$, and urogenital system carcinomas ( $\mathrm{HR}=1.53,95 \% \mathrm{Cl}$ : 1.19-1.96, $P=0.0008)$ (Figure 4A). Next, we performed subgroup analyses stratified by cut-off value, and high PVT1 expression was significantly associated with poor OS in the studies using median $(\mathrm{HR}=2.04,95 \% \mathrm{Cl}$ : 1.62-2.57, $P<0.00001)$ and others $(H R=1.93,95 \% \mathrm{Cl}: 0.89-4.15$, $P=0.09$ ) (Figure 4B). Then, we divided the studies into two categories according to the sample size using 100 patients as a threshold. In this analysis, upregulated PVT1 expression was a strong prognostic marker for poor OS both in larger sample sizes $(H R=1.52,95 \%$ $\mathrm{Cl}$ : 1.33-1.73, $P<0.00001)$ and smaller sample sizes $(\mathrm{HR}=2.62$, 


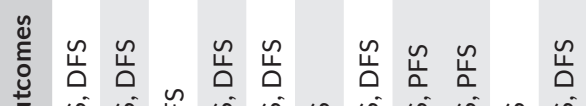

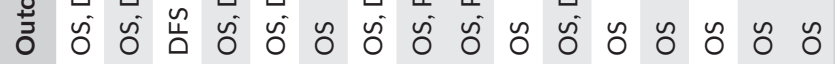

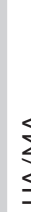

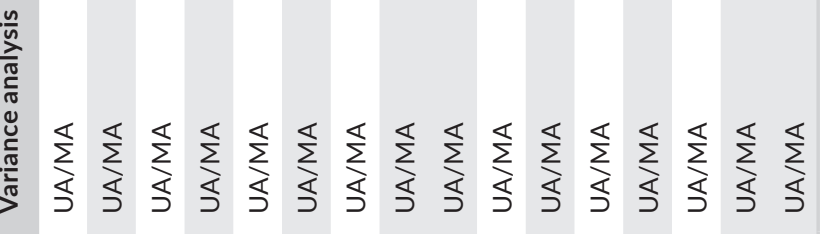

产芯

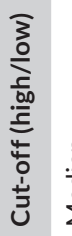

$\frac{0}{\frac{\partial}{5}}$

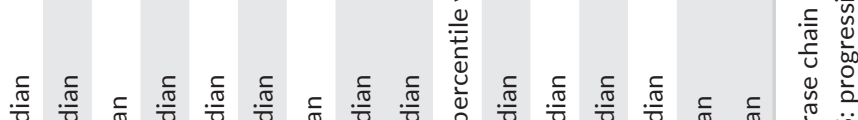
¿̇ं

$\frac{\sqrt{\pi}}{\frac{\pi}{5}}$

要

要

$\begin{array}{ll} & \\ & \\ 0\end{array}$

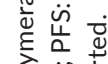

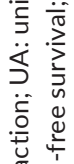

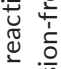

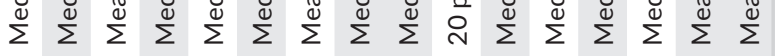

을

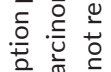

突

政

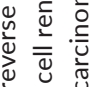

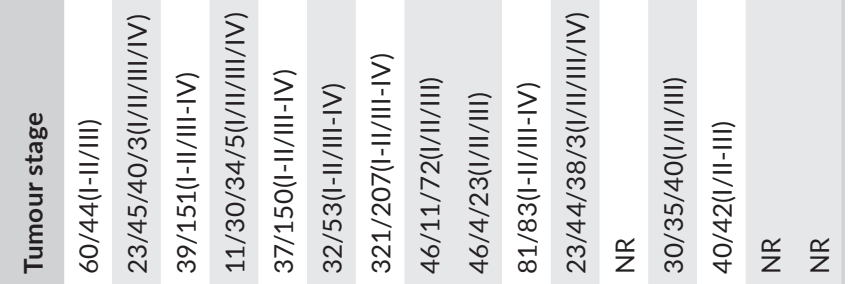

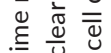

产㣢

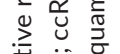

焉竞离

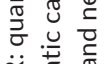

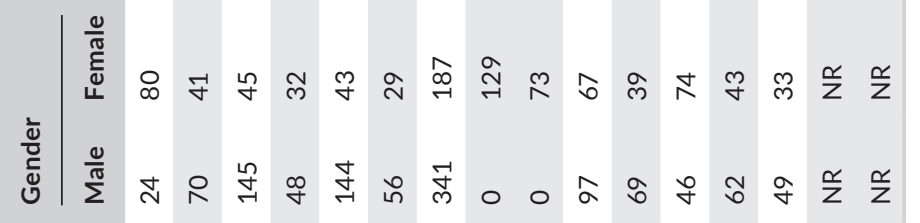

政

定

论

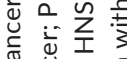

$\frac{n}{\sqrt{2}}$

茜

过

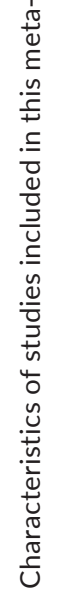

苛 云

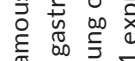

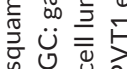

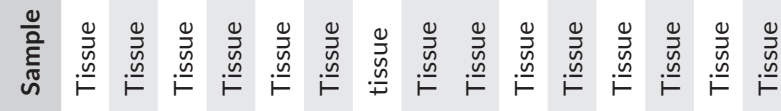

ब्ष

鱼

들

紊

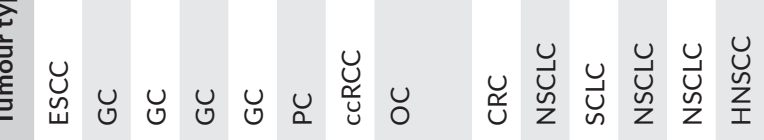

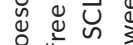

نे

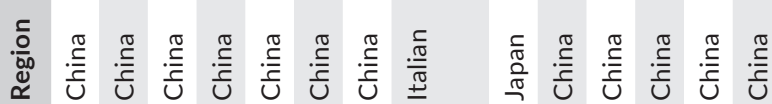

出哭

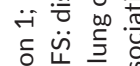

差这

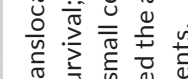

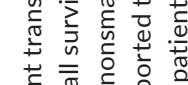

类

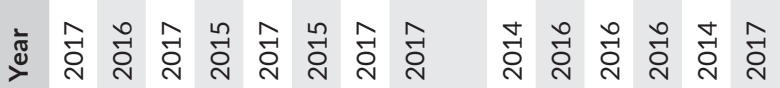

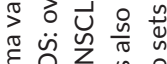

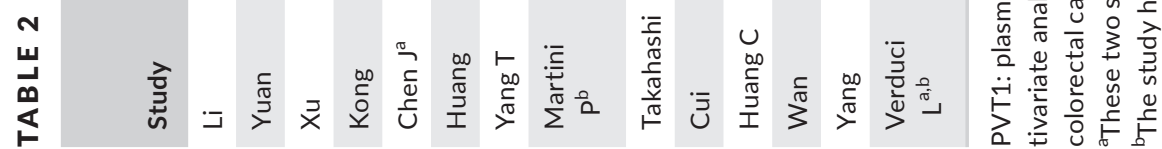




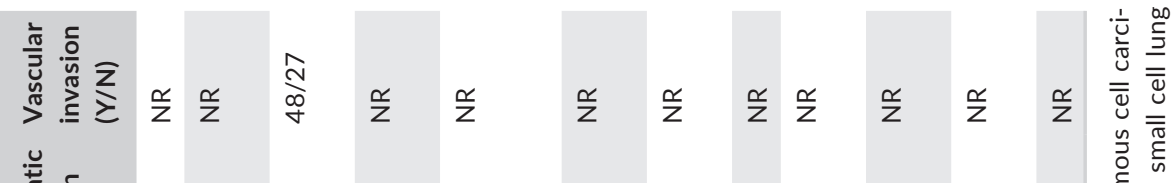
蒙

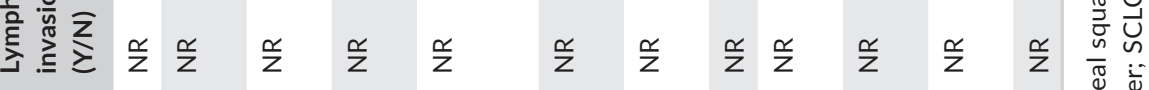

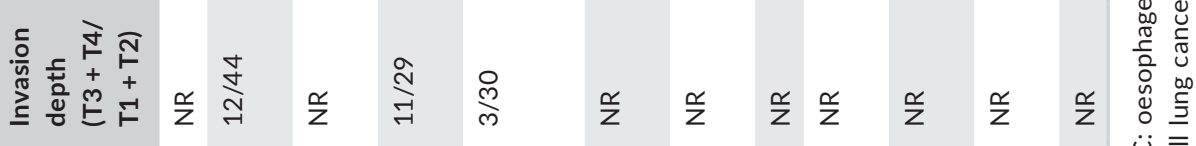

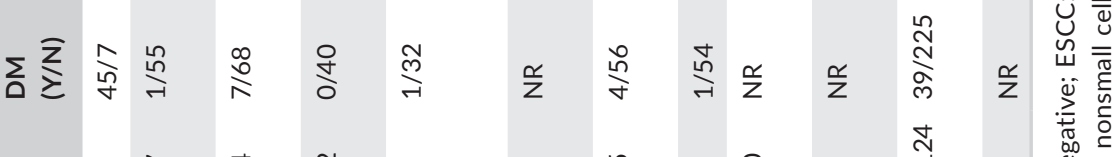

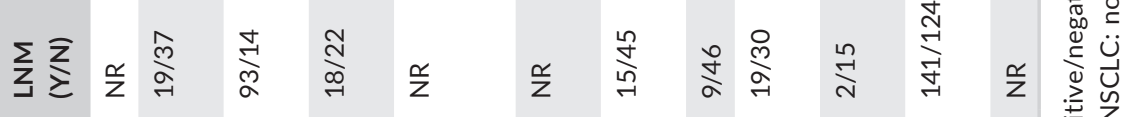
点

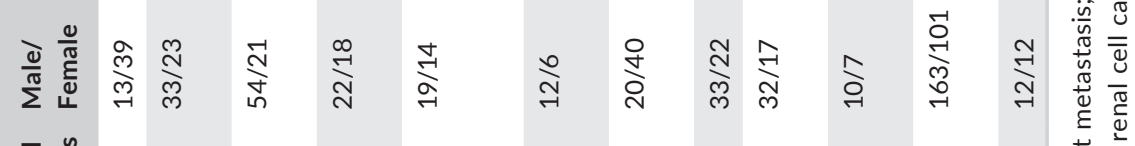

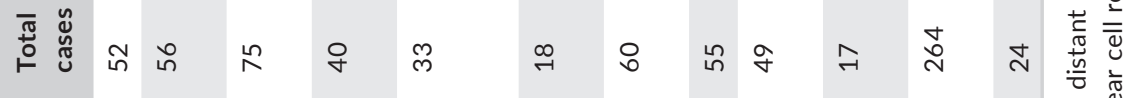

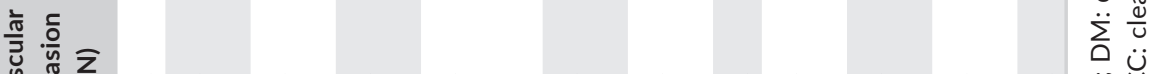

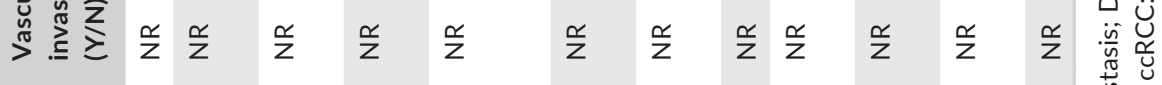
들

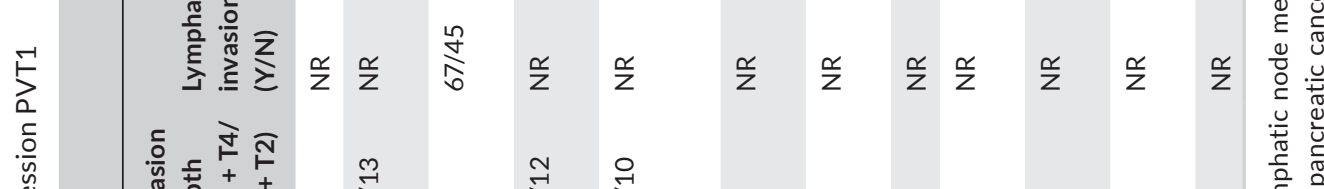

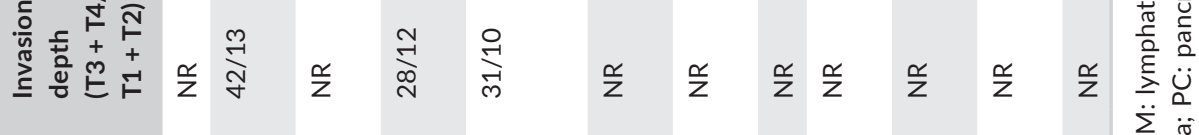

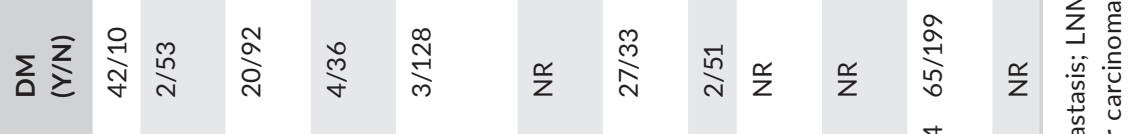

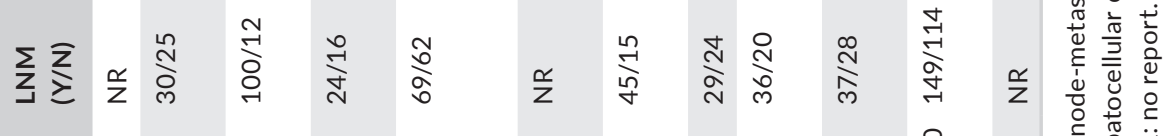
垔

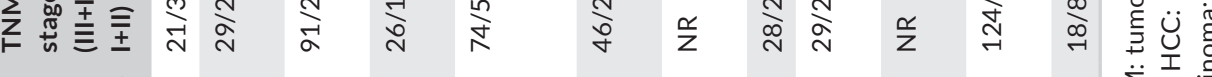

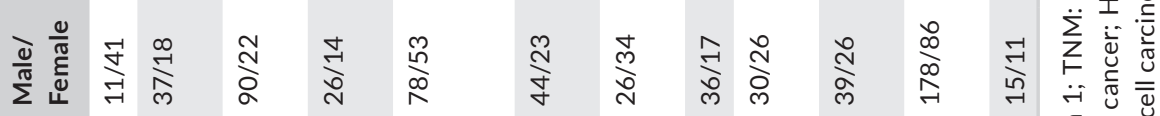

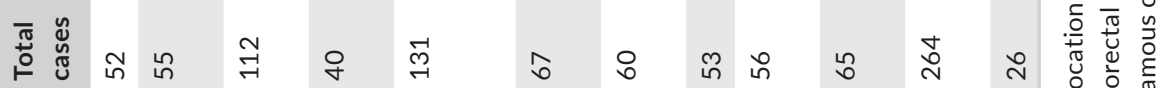

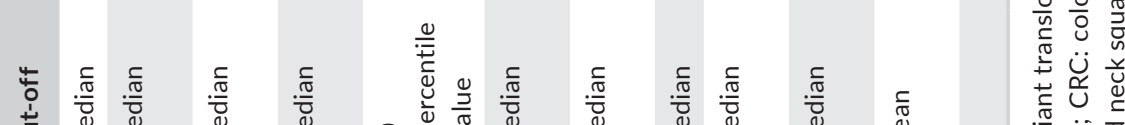

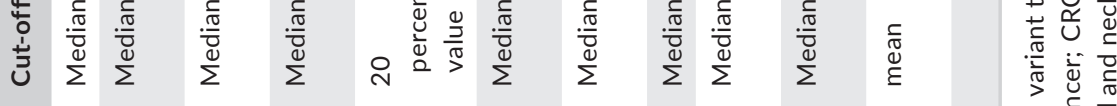

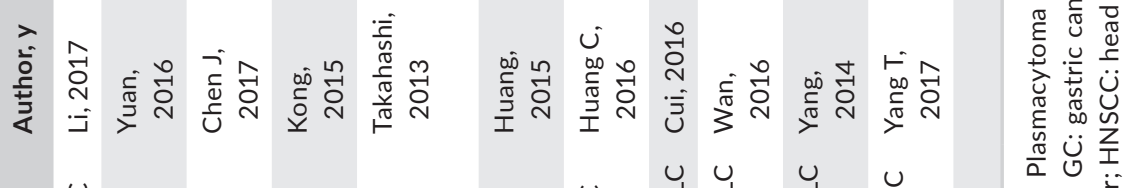

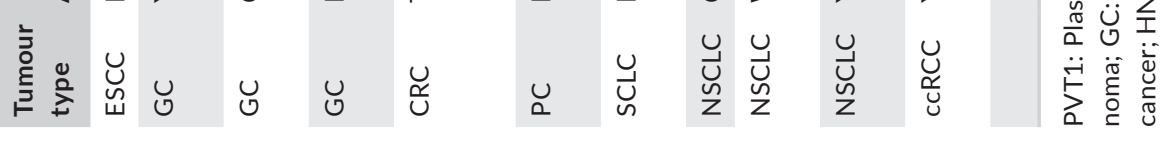


FIGURE 3 Forest plots of hazard ratios for the association between PVT1 expression and overall survival (A), disease-free survival (B), and the association between circle-PVT1 expression and overall survival (C) in cancer patients

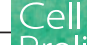

Proliferation

WILEY

(A)

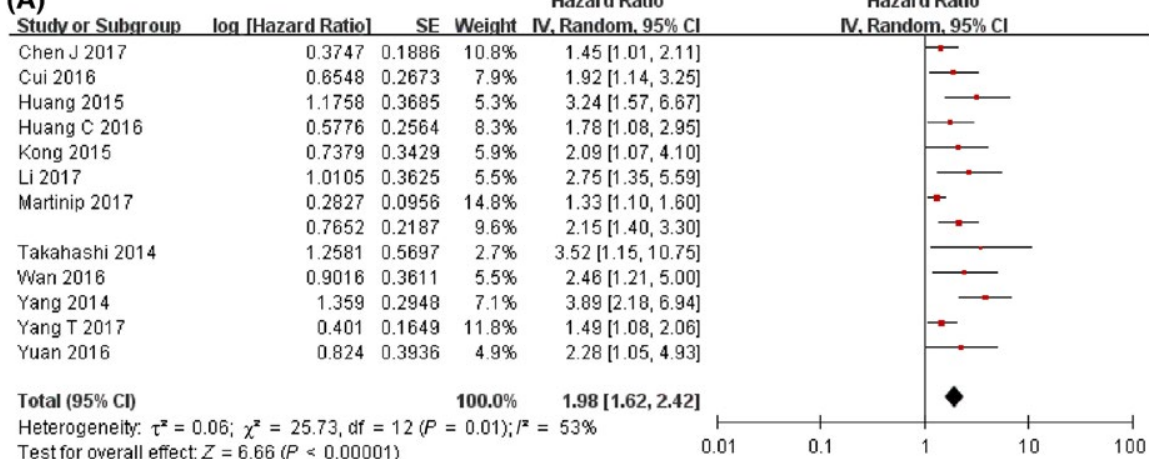

Test for overall effect: $Z=6.66(P<0.00001)$

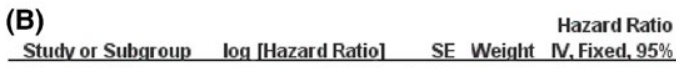

Chen J 2017 0.3606 $0.185 \quad 10.9 \%$

Cui 2016

Kong 2015

Martinip 2017

Xu 2017

Yang T 2017

Yuan 2016

$\begin{array}{rrrr}0.3606 & 0.185 & 10.9 \% & 1.43[1.00,2.06] \\ 0.8093 & 0.3372 & 3.3 \% & 2.25[1.16,4.35]\end{array}$

$\begin{array}{llll}0.8093 & 0.3372 & 3.3 \% & 2.25[1.16,4.35] \\ 0.7956 & 0.3436 & 3.2 \% & 2.22[1.13,4.35]\end{array}$

$\begin{array}{llll}0.7956 & 0.3436 & 3.2 \% & 2.22[1.13,4.35]\end{array}$

$\begin{array}{llll}0.5254 & 0.1342 & 20.8 \% & 1.69\end{array}[1.30,2.20]$

$\begin{array}{lllll}0.4521 & 0.0968 & 39.9 \% & 1.57[1.30,1.90]\end{array}$

$\begin{array}{llll}0.5013 & 0.1907 & 10.3 \% & 1.65[1.14,2.40]\end{array}$

$\begin{array}{llll}0.3846 & 0.2086 & 8.6 \% & 1.47[0.98,2.21]\end{array}$

$\begin{array}{llll}0.7929 & 0.3508 & 3.0 \% & 2.21\end{array}[1.11,4.39]$

Total $(95 \% \mathrm{Cl})$

Heterogeneity: $\chi^{2}=3.40, \mathrm{df}=7(P=0.85) ; /^{\mathbf{2}}=0 \%$

Test for overall effect: $Z=8.00(P<0.00001)$

$100.0 \% \quad 1.63[1.45,1.84]$

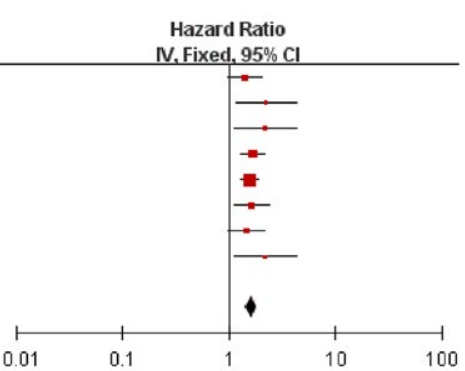

(C)

Study or Subgroup log [Hazard Ratio] SE Weight IV, Random, 95\% C

$\begin{array}{lllll}\text { Chen J } 2017 & -0.5181 & 0.1868 & 37.6 \% & 0.60[0.41,0.86]\end{array}$

$\begin{array}{lrrrr}\text { Martinip } 2017 & 0.5217 & 0.2977 & 34.0 \% & 1.68[0.94,3.02]\end{array}$

$\left.\begin{array}{llll}0.7301 & 0.4435 & 28.4 \% & 2.08[0.87,4.95\end{array}\right]$

Total $(95 \% \mathrm{Cl}) \quad 100.0 \% \quad 1.21[0.52,2.83]$

Heterogeneity. $\tau^{2}=0.46 ; \chi^{2}=12.86$, df $=2(P=0.002) ; I^{2}=84 \%$

Test for owerall effect: $Z=0.44(P=0.66)$

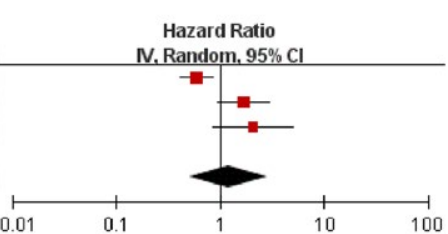

TAB LE 4 Subgroup meta-analysis of pooled hazard ratios for overall survival

\begin{tabular}{|c|c|c|c|c|c|c|c|}
\hline Categories & Studies (n) & $\begin{array}{l}\text { Total cases of } \\
\text { patients }\end{array}$ & $\mathrm{HR}(95 \% \mathrm{Cl})$ & $P$-value & Model & \multicolumn{2}{|c|}{ Heterogeneity } \\
\hline Overall survival & 12 & 1876 & $1.98(1.62,2.42)$ & $<0.00001$ & Random & $53 \%$ & 0.01 \\
\hline \multicolumn{8}{|l|}{ Cancer type } \\
\hline $\begin{array}{l}\text { Digestive system } \\
\text { cancers }\end{array}$ & 6 & 731 & $2.13(1.57,2.89)$ & $<0.00001$ & Fixed & $22 \%$ & 0.27 \\
\hline $\begin{array}{l}\text { Urogenital system } \\
\text { cancers }\end{array}$ & 2 & 730 & $1.53(1.19,1.96)$ & 0.0008 & Random & $52 \%$ & 0.13 \\
\hline \multicolumn{8}{|l|}{ Cut-off (high/low) } \\
\hline Median & 10 & 1184 & $2.04(1.62,2.57)$ & $<0.00001$ & Random & $57 \%$ & 0.009 \\
\hline$\leq 100$ & 4 & 320 & $2.62(1.98,3.48)$ & $<0.00001$ & Fixed & $11 \%$ & 0.34 \\
\hline
\end{tabular}

$\mathrm{Cl}$ : confidence interval.

95\% Cl: 1.98-3.48, $P<0.00001$ ) (Figure 4C). Two studies reported the association between circPVT1 expression and OS, but no significance was found $(\mathrm{HR}=1.21,95 \% \mathrm{Cl}: 0.52-2.83, P=0.66)$ as shown in Figure $3 \mathrm{C}$.

\section{3 | Association between PVT1 and DFS in cancers}

Seven studies comprising 1406 patients reported the prognostic value of PVT1 for DFS or PFS. As shown in Figure 3B, PVT1 
Test for overall effect $Z=6.65(P<0.00001)$

Test for subaroun differences: $\chi^{2}=4.75 . \mathrm{df}=2(P=0.09) \cdot I^{2}=57.9 \%$

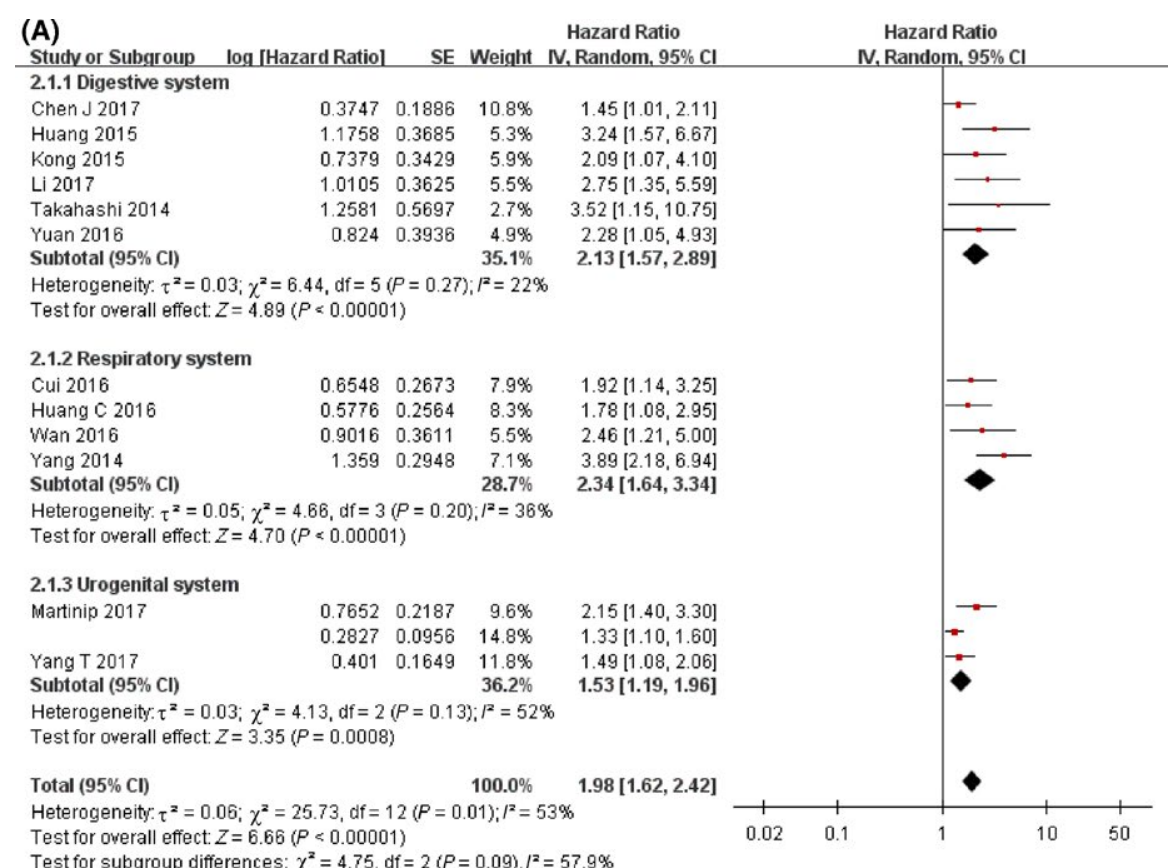

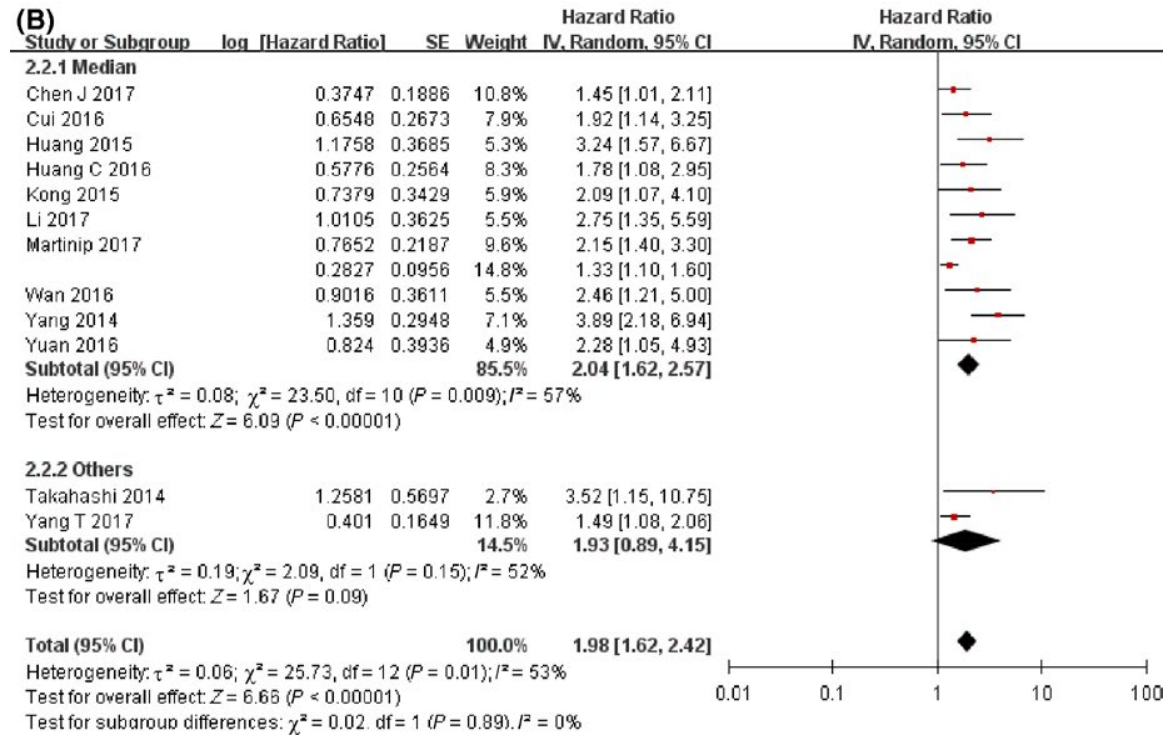

FIGURE 4 Forest plot of hazard ratios for the association between PVT1 expression and overall survival in subgroup analysis based on different cancer types (A), cut-off (B), and sample size (C) overexpression was a negative factor for DFS ( $\mathrm{HR}=1.63,95 \% \mathrm{Cl}$ : 1.45-1.84, $P<0.00001)$ with no significant heterogeneity among studies $\left(I^{2}=0 \%, P=0.85\right)$. Then, we conducted subgroup analyses based on cancer type, sample size, and cut-off value. These data are presented in Table 5 and supplementary Figures S1-S3. The stratified analysis by cancer type indicated a significant association between increased PVT1 expression and poor DFS in patients with digestive system carcinomas $(\mathrm{HR}=1.70,95 \% \mathrm{Cl}$ : 1.36-2.13, $P<0.00001)$. Then, high PVT1 expression was significantly related to poor DFS in the studies using median $(H R=1.64$, 95\% Cl: 1.45-1.86, $P<0.00001)$ as the cut-off value. In addition, upregulated PVT1 expression was a strong prognostic marker for poor DFS in studies with large sample sizes $(\mathrm{HR}=1.61,95 \% \mathrm{Cl}$ : $1.40-1.84, P<0.00001)$ or with small sample sizes ( $H R=1.75,95 \%$ $\mathrm{Cl}$ : 1.37-2.24, $\mathrm{P}<0.00001)$ using 100 patients as the threshold to group. Given that all these stratified analyses exhibit no heterogeneity, a fixed-effect model was applied.

\subsection{Association between PVT1 and clinicopathological characteristics}

The pooled ORs and $95 \% \mathrm{Cls}$ of the clinicopathological characteristics for all the enrolled studies are presented in Table 6 and Figures S4-S9. There are 9 studies with 1517 patients, 7 studies with 1298 patients, 10 studies with 1076 patients, 2 studies with 351 patients, and 2 studies with 191 patients reporting the association between PVT1 expression and LNM, DM, TNM stage, lymphatic invasion, and invasion depth, respectively. The pooled results indicated that elevated PVT1 expression was significantly associated with positive LNM (OR $=2.87,95 \%$ 
FIGURE 4 Continued

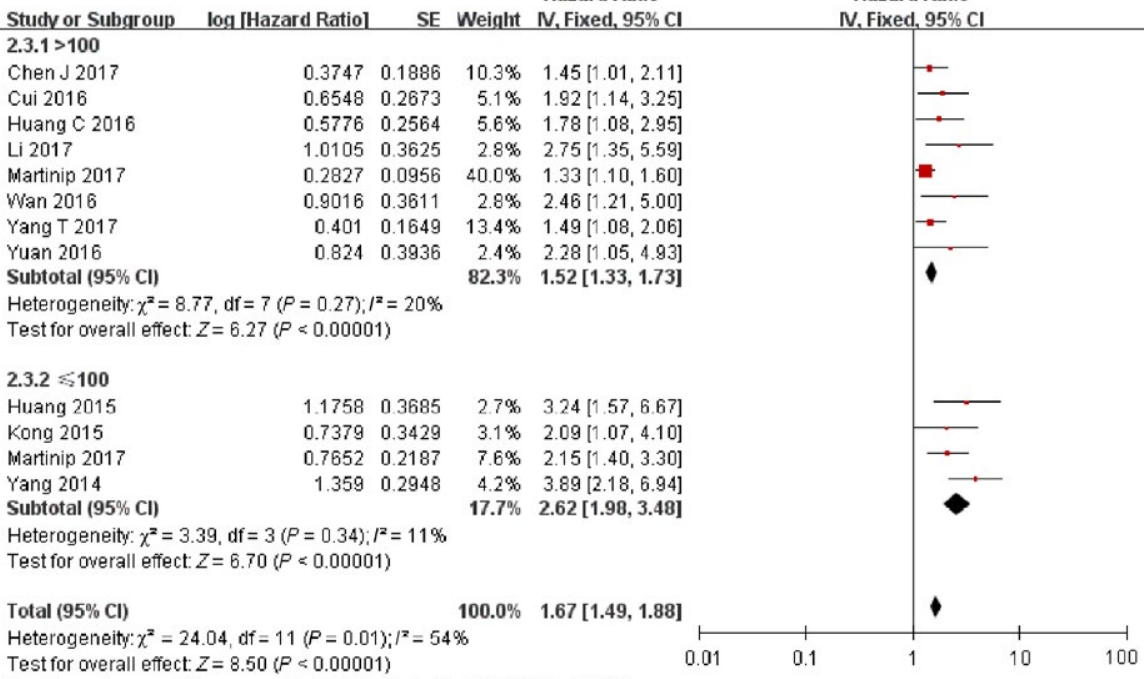

Test for overall effect: $Z=8.50(P<0.00001)$

Test for subaroun differences: $\chi^{2}=11.89 . \mathrm{df}=1(P=0.0006) \cdot I^{2}=91.6 \%$

TAB LE 5 Subgroup meta-analysis of pooled hazard ratios for disease-free survival

\begin{tabular}{|c|c|c|c|c|c|c|c|}
\hline Categories & Studies (n) & $\begin{array}{l}\text { Total cases of } \\
\text { patients }\end{array}$ & Hazard ratio $(95 \% \mathrm{Cl})$ & $P$-value & Model & \multicolumn{2}{|c|}{ Heterogeneity } \\
\hline Disease-free survival & 7 & 1406 & $1.63(1.45,1.84)$ & $<0.00001$ & Fixed & $0 \%$ & 0.85 \\
\hline \multicolumn{8}{|l|}{ Cancer type } \\
\hline $\begin{array}{l}\text { Digestive system } \\
\text { cancers }\end{array}$ & 4 & 568 & $1.70(1.36,2.13)$ & $<0.00001$ & Fixed & $0 \%$ & 0.57 \\
\hline \multicolumn{8}{|l|}{ Cut-off (high/low) } \\
\hline Median & 6 & 1216 & $1.64(1.45,1.86)$ & $<0.00001$ & Fixed & $0 \%$ & 0.79 \\
\hline Others $^{a}$ & 1 & 190 & $1.73(1.21,2.48)$ & 0.003 & NA & NA & NA \\
\hline \multicolumn{8}{|l|}{ Sample sizes $^{b}$} \\
\hline
\end{tabular}

$\mathrm{Cl}$ : confidence interval; NA: not applicable.

${ }^{\text {a }}$ The heterogeneity is not applicable, for there is only one study in this subgroup.

${ }^{b}$ One study has two sets of patients.

TAB LE 6 Meta-analysis of the association between PVT1 expression and clinicopathological characteristics

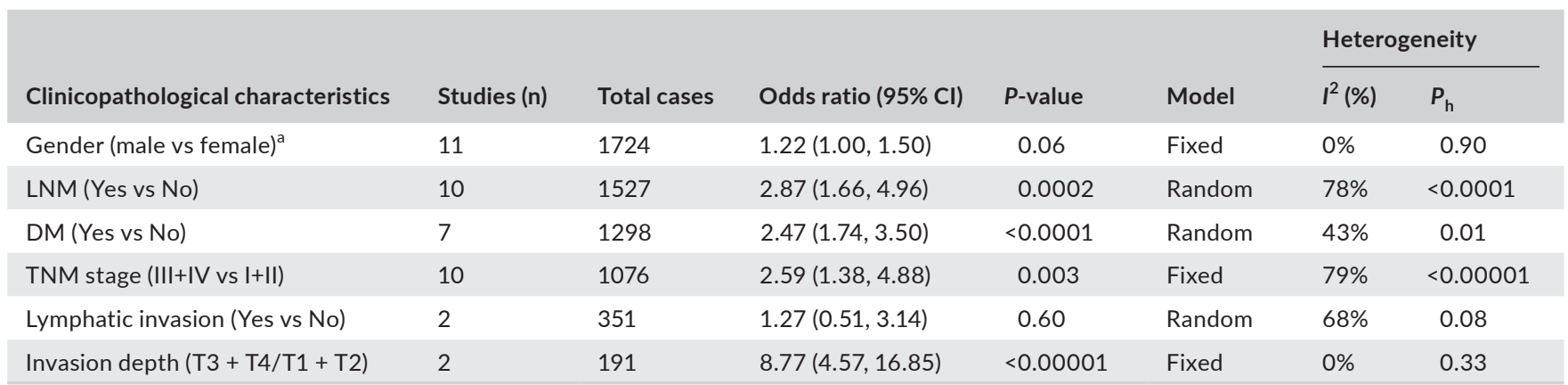

PVT1: plasmacytoma variant translocation 1; Cl: confidence interval; LNM: lymphatic node metastasis; DM: distant metastasis; TNM: tumour-node-metastasis.

${ }^{a}$ The study about ovarian cancer was not involved because there were only female patients in the study. 
Cl: 1.66-4.96, $P=0.0002)$, positive DM $(O R=2.47,95 \% \mathrm{Cl}$ : 1.74-3.50, $P<0.00001)$, advanced TNM stage $(O R=2.59,95 \% \mathrm{Cl}$ : 1.38-4.88, $P=0.003)$, and advanced invasion depth $(O R=8.77$, 95\% Cl: 4.57-16.85, $P<0.00001)$. However, no significant association was found between overexpression of PVT1 and gender $(\mathrm{OR}=1.22,95 \% \mathrm{Cl}: 1.00-1.50, P=0.06)$ and positive lymphatic invasion (OR $=1.27,95 \% \mathrm{Cl}$ : 0.51-3.14, $P=0.60)$.

\section{4 | DISCUSSION}

In recent years, an increasing number of studies demonstrated that IncRNAs were abnormally expressed in various cancers and some could even serve as potential markers for diagnosis, prognosis, and treatment in malignant tumours. Therefore, numerous reviews or meta-analysis articles, including our study, have been used to reveal the correlation between IncRNAs and cancer progression and prognosis. ${ }^{47,52}$

The PVT1 gene was first discovered in 1983 in mouse as frequently involved in plasmacytomas. ${ }^{9,53}$ Shortly thereafter, the PVT1 locus also emerged in human Burkitt's lymphomas as a site of variant translocations. ${ }^{54}$ Since then, PVT1 has been an area of focused research especially in recent decades, which is reflected by the increasing number of publications related to PVT1 as shown in Figure 1. Many studies reported overexpression of PVT1 in both various cancer tissues and cell lines and demonstrated a negative association between PVT1 expression and patients' prognosis. In our metaanalysis, we explored the relationship between PVT1 expression level and cancer prognostic parameters. Our results demonstrated that high PVT1 expression predicted poor OS $(\mathrm{HR}=1.98,95 \% \mathrm{Cl}$ : 1.62-2.42, $P<0.00001)$ and DFS (HR=1.63, 95\% Cl: $1.45-1.84$, $P<0.00001)$ for cancer patients. Given that significant heterogeneity was noted when we analysed the association between PVT1 expression and OS, we analysed the data based on cancer type and found that elevated PVT1 expression was significantly related with poor OS for patients with digestive system cancers (HR $=2.13,95 \%$ $\mathrm{Cl}: 1.57-2.89, P<0.00001)$, respiratory system cancers $(\mathrm{HR}=2.34$, $95 \% \mathrm{Cl}: 1.64-3.34, P<0.00001)$, and urogenital system cancers ( $\mathrm{HR}=1.53,95 \% \mathrm{Cl}: 1.19-1.96, P=0.0008)$. Subgroup analyses based on types of cancer also indicated that PVT1 overexpression was significantly associated with poor DFS for patients with GCs (HR $=1.70$, 95\% Cl: 1.36-2.13, $P<0.00001)$; and fixed-effect model was applied for no substantial heterogeneity $\left(I^{2}=0 \%, P=0.57\right)$ existed. And for other system cancers, including one NSCLC, one CCRCC, and one OC, the result indicated a significant relation between PVT1 overexpression and poor DFS (HR $=1.62,95 \% \mathrm{Cl}: 1.41-1.86, P<0.00001)$ without substantial heterogeneity $\left(I^{2}=0 \%, P=0.71\right)$. In addition, patients with high PVT1 expression in tumour tissues were more prone to advanced TNM stages $(\mathrm{OR}=2.59,95 \% \mathrm{Cl}$ : $1.38-4.88$, $P=0.003)$. Furthermore, upregulated PVT1 expression was associated with positive $\mathrm{LNM}(\mathrm{OR}=2.89,95 \% \mathrm{Cl}: 1.66-4.96, P=0.0002)$ and positive $\mathrm{DM}(\mathrm{OR}=2.47,95 \% \mathrm{Cl}: 1.74-3.50, P<0.0001)$, indicating that patients with a higher PVT1 expression in tumour tissues may exhibit an increased risk of tumour metastasis. Two studies with a total of 191 cases reported the association between invasion depth of GC and PVT1 expression. The results indicated that PVT1 overexpression is positively related with advanced invasion depth ( $\mathrm{OR}=8.77,95 \% \mathrm{Cl}$ : 4.57-16.85, $\mathrm{P}<0.00001)$. Numerous studies reported that later TNM stage, positive vascular invasion, LNM, DM, and advanced invasion depth are all vital prognostic factors and significantly correlated with poor OS and DFS for patients. ${ }^{55,56}$ Overall, our meta-analysis results indicated that high PVT1 expression could be an indicator of positive metastasis and poor prognosis in cancer patients.

Studies have demonstrated that PVT1 may function in the genesis, development, chemoresistance and radioresistance of diseases, mainly tumours via various mechanisms, including participating in DNA rearrangements, encoding miRNAs, or interacting with MYC. ${ }^{57}$ Recently, a completely different function of PVT1 was demonstrated by new findings that highlight its involvement as a competing RNA (ceRNA) to miRNAs to protect mRNAs from miRNAs repression. Therefore, we summarized all the PVT1-related miRNAs, their targets, and how their interactions affect tumour genesis and progression (Table 7). Paci et al noted that PVT1 acts as ceRNA with a preferential net binding towards the miR-200 family in the normal miRNA-mediated interactions network but not in breast cancer. These researches hypothesized that the abolishment of the ceRNA activity of PVT1 was prompted by the existence of multiple isoforms of PVT1. ${ }^{58}$ This meta-analysis included four studies related to lung cancer, and analysis results suggested that PVT1 overexpression was associated with poor OS $(\mathrm{HR}=2.34$, 95\% Cl: 1.64-3.34, $P<0.00001)$ for lung cancer patients. Five studies reported the association between PVT1 and miRNAs and their interaction and possible mechanisms in the genesis and development of lung cancer. ${ }^{21,22,59-61}$ Chen et al ${ }^{59}$ found that PVT1 directly binds to miR-200a-5p and miR-200b-5p to block their inhibition on matrix metallopeptidase 9 (MMP-9), increasing the expression of MMP-9 and thus promoting tumour cell invasion in NSCLC. Taken together, the PVT1-miR200a/b-MMP9 axis may be a potential target for NSCLC patients. In another study, PVT1 was found to sponge to miR-195 and inhibit its expression, consequently promoting cell proliferation and cell colony formation, inhibiting cell apoptosis, reducing radiosensitivity in NSCLC cells in vitro and in vivo. ${ }^{60}$ Similarly, PVT1 directly binds to miR-497 and inhibits the expression of miR-497, subsequently improving cell viability, promoting cell invasion, and inhibiting cell apoptosis in NSCLC cells. ${ }^{22}$ HIF-1a overexpression is noted in a large number of human tumours, correlating with poor prognosis and treatment failure. ${ }^{61}$ PVT1 also competes for miR-199a-5p in NSCLC to promote the downstream of expression of HIF-1a, thus promoting tumour cells proliferation and invasion. ${ }^{62}$ Overall, PVT1-miRNAs play a vital role in the development and progression of NSCLC and could represent a potential target for NSCLC patients. Four studies related to GC meeting the inclusion criteria were enrolled in this meta-analysis, and the results indicated that upregulation of PVT1 expression was associated with poor OS and DFS for GC patients. Moreover, interaction between PVT1 and 
TAB LE 7 MicroRNAs interacting with PVT1 in the genesis and development of cancers

\begin{tabular}{|c|c|c|c|c|c|c|}
\hline MicroRNAs & Cancer type & $\begin{array}{l}\text { Interaction with } \\
\text { PVT1 }\end{array}$ & $\begin{array}{l}\text { Correlation } \\
\text { with PVT1 }\end{array}$ & $\begin{array}{l}\text { Potential target } \\
\text { genes }\end{array}$ & Function & References \\
\hline miR-146a & Pancreatic cancer & - & Negative & $\begin{array}{l}\text { DNMT1, DNMT3a, } \\
\text { and DNMT3b }\end{array}$ & $\begin{array}{l}\text { Cell apoptosis, cell } \\
\text { viability }\end{array}$ & 64 \\
\hline miR-152 & Gastric cancer & Direct binding & Negative & CD151, FGF2 & - & 16 \\
\hline miR186-5p & $\begin{array}{l}\text { Hepatocellular } \\
\text { carcinoma }\end{array}$ & Direct binding & Negative & YAP-1 & $\begin{array}{l}\text { Cell proliferation, } \\
\text { invasion, migration, and } \\
\text { apoptosis }\end{array}$ & 29 \\
\hline miR-186 & Glioma & Direct binding & Negative & Atg7, Beclin1 & $\begin{array}{l}\text { Cell proliferation, } \\
\text { migration, tube } \\
\text { formation, autophago- } \\
\text { some formation }\end{array}$ & 65 \\
\hline miR-186 & Gastric cancer & Direct binding & Negative & HIF-1a & $\begin{array}{l}\text { Cell proliferation and } \\
\text { invasion }\end{array}$ & 5 \\
\hline miR-195 & Osteosarcoma & Direct binding & Negative & $\begin{array}{l}\text { BCL2, CCND1, and } \\
\text { FASN }\end{array}$ & $\begin{array}{l}\text { Cell proliferation, } \\
\text { migration, invasion, and } \\
\text { apoptosis }\end{array}$ & 36 \\
\hline miR-195 & Cervical cancer & Direct binding & Negative & $\begin{array}{l}\text { EZH2, E-cadherin, } \\
\text { fibronectin, } \\
\text { vimentin, cas- } \\
\text { pase-3, Smad3 }\end{array}$ & $\begin{array}{l}\text { Cell proliferation and cell } \\
\text { viability, and enhanced } \\
\text { cell apoptosis }\end{array}$ & 32 \\
\hline miR199a-5p & $\begin{array}{l}\text { Nonsmall cell lung } \\
\text { cancer }\end{array}$ & Direct binding & Negative & HIF- $1 \alpha$ & Cell proliferation & 62 \\
\hline $\begin{array}{l}\mathrm{miR}-200 \mathrm{a}- \\
5 \mathrm{p} / \mathrm{b}-5 \mathrm{p}\end{array}$ & $\begin{array}{l}\text { Nonsmall cell lung } \\
\text { cancer }\end{array}$ & Direct binding & Negative & MMP9 & Cell invasion & 59 \\
\hline miR-214 & $\begin{array}{l}\text { Hepatocellular } \\
\text { carcinoma }\end{array}$ & - & Negative & $\mathrm{EZH} 2$ & $\begin{array}{l}\text { Cell proliferation and } \\
\text { invasion }\end{array}$ & 28 \\
\hline miR-26b & Melanoma & Direct binding & Negative & - & $\begin{array}{l}\text { Cell proliferation, } \\
\text { apoptosis }\end{array}$ & 38 \\
\hline $\mathrm{miR}-26$ & Lung cancer & Direct binding & Negative & SLC7A5 & Cell proliferation & 21 \\
\hline miR-424 & Cervical cancer & Direct binding & Negative & - & $\begin{array}{l}\text { Cell proliferation, } \\
\text { migration, invasion }\end{array}$ & 63 \\
\hline miR-448 & Pancreatic cancer & Direct binding & Negative & SERBP1 & $\begin{array}{l}\text { Cell proliferation and } \\
\text { migration }\end{array}$ & 26 \\
\hline miR-497 & Osteosarcoma & Direct binding & Negative & HK2 & $\begin{array}{l}\text { Cell proliferation, } \\
\text { invasion, and apoptosis }\end{array}$ & 37 \\
\hline miR-497 & $\begin{array}{l}\text { Nonsmall cell lung } \\
\text { cancer }\end{array}$ & Direct binding & Negative & - & $\begin{array}{l}\text { Cell viability, invasion, } \\
\text { and apoptosis }\end{array}$ & 22 \\
\hline
\end{tabular}

PVT1: plasmacytoma variant translocation 1; DNMT1: deoxyribonucleic acid methyltransferases 1; DNMT3a: deoxyribonucleic acid methyltransferases 3a; DNMT3b: deoxyribonucleic acid methyltransferases 3b; CD151: Cluster of differentiation 151; FGF2: fibroblast growth factor 2; YAP-1: yes-associated protein 1; BCL2: b-cell lymphoma 2 protein; CCND1: cyclin D1; FASN: fatty acid synthase; EZH2: enhancer of zeste homologue 2; HIF-1 $\alpha$ : hypoxia-inducible factors 1 $\alpha$; MMP9: matrix metallopeptidase 9; BMI1: b cell-specific Moloney 1; ZEB1: zincfinger ebox-binding homeobox 1; ZEB2: zincfinger ebox-binding homeobox 1; LASP1: lim and SH3 domain protein; SLC7A5: solute carrier transporter 7a5; SERBP1: serpine mRNA-binding protein 1; HK2: hexokinase 2. 
miRNAs also contributed to the occurrence of GC. PVT1 targets miR-152 and decreases its expression, subsequently improving the expression of cluster of differentiation 151 (CD151) and fibroblast growth factor 2 (FGF2). These effects ultimately promote GC cells proliferation and motility. ${ }^{16}$ PVT1 directly targets miR-186 to promote the downstream of expression of HIF-1a, thus promoting tumour cell proliferation and invasion in GC. ${ }^{5}$

PVT1 also promotes the genesis and facilitates the progression of other types of cancers via competing or interacting with miRNAs. Zhang et $\mathrm{al}^{30}$ indicated that PVT1 targets zeste homologue 2 (EZH2) and recruits EZH2 to the miR-200b promoter, increasing the methylation level of miR-200b and inhibiting its expression. Downregulation of miR-200b enhances tumour cell proliferation and invasion in CC. PVT1 also recruits EZH2 to the promoter of other miRNAs, such as miR-214, to increase its trimethylation level and decrease its expression in HCC cells, thus promoting tumour cell proliferation and invasion. ${ }^{28}$ Numerous other miRNAs are also involved in the interaction with PVT1 in cancers. PVT1 may act as a ceRNA to negatively modulate miR-424 in CC cells. ${ }^{63}$ Liu et $\mathrm{al}^{62}$ reported that PVT1 inhibited the expression of miR-146a through inducing methylation of the $\mathrm{CpG}$ island in its promoter, thus inhibiting PC apoptosis. Another study suggested that PVT1 served as an endogenous sponge for miR-186-5p to reduce its inhibiting effect on yes-associated protein 1 (YAP-1) in hepatic cancer cells, promoting cell proliferation, invasion, and migration and inhibiting cell apoptosis. ${ }^{29} \mathrm{Ma}$ et al ${ }^{65}$ revealed that PVT1 increased the expression of Atg7 and Beclin1 via directly targeting miR-186, thus inducing protective autophagy and promoting glioma vascular endothelial cell proliferation, migration, and angiogenesis. Moreover, PVT1 is also involved in the treatment of cancers. Paclitaxel (PTX) treatment in CC cells significantly induced downregulation of E-cadherin and upregulation of fibronectin and vimentin. PVT1 directly binds to miR-195. PVT1 overexpression and miR-195 downregulation significantly inhibited PTX-induced suppression of cell viability and apoptosis. $^{32}$

CircRNAs were first identified from spliced transcripts of a candidate tumour suppressor gene in $1991 .{ }^{66}$ Given rapid advances in high-throughput sequencing techniques, a large number of circRNAs have been discovered. For example, hsa circ_002059 is significantly downregulated in GC tissues compared with paired adjacent nontumour tissues; low expression of hsa_circ_002059 was significantly correlated with DM and TNM, suggesting that hsa_circ_002059 may be a potential stable biomarker for the diagnosis of GC. ${ }^{41}$ In contrast, only a few studies have reported that the expression and function of circPVT1 in human diseases to date. CircPVT1, which was first identified as has-circRNA 6 by Memczak et al, ${ }^{40}$ originates from the PVT1 transcript. CircPVT1 is a 410-nt long circRNA and results from the circularization of PVT1 exon2 ${ }^{15,34,44,67}$ Panda et al ${ }^{67}$ revealed that knockdown of circPVT1 in proliferating fibroblasts triggered senescence and reduced cell proliferation with an increase in senescence-associated $\beta$-galactosidase activity and increased cyclin-dependent kinase inhibitor 1A (CDKN1A)/P21 and TP53 levels. Moreover, circPVT1 directly binds to let-7 and antagonizes endogenous let-7 triggered cell proliferation. ${ }^{67}$ Verduci L et al ${ }^{34}$ found that circPVT1 was upregulated in HNSCC tissues, and high expression of circPVT1 correlated with poor OS. CircPVT1 expression in HNSCC is transcriptionally enhanced by the mutated p53/Yes-Associated Protein/TEA Domain Family Member 1 (mut-p53/YAP/TEAD1) complex, which does not affect the expression of linear PVT1. In addition, circPVT1 behaves as an oncogene modulating the expression of mut-p53-associated miR-497-5p and downstream genes involved in the control of cell proliferation. Another publication demonstrated that circPVT1 was upregulated in GC tissues partly due to DNA amplification. In addition, circPVT1 promotes cell proliferation by sponging miR-125 family members to inhibit its activity and facilitating E2F2 expression. ${ }^{15}$ However, partly contrary to Lorena's findings, low circPVT1 expression was related to poor OS and DFS for GC patients. ${ }^{15}$ The circRNAs are more stable than associated linear mRNAs in vivo given their resistance to RNase activity; ${ }^{40,68}$ hundreds of circRNAs are more abundant in blood than corresponding linear mRNAs. ${ }^{69}$ Therefore, further studies are needed to explore the expression of circPVT1 in tumours and its function in carcinogenesis and development. In addition, circPVT1 may be a more potent biomarker of prognosis or detection in for tumour patients.

Nevertheless, there are some limitations in this work. First, studies with positive results were more likely to be published compared with those with negative results. We only enrolled studies published up to 1 February 2018. Thus, data from negative and ongoing studies were underrepresented. Hence, the role of PVT1 in tumour prognosis may be overestimated. Furthermore, cancer patient survival largely depends on the therapeutic regimens; thus, different treatments differently influence on the calculation of HR or OR values. In addition, only English- or Chinese-language publications were included in this meta-analysis, so studies in other languages demonstrating the association of PVT1 expression and cancer patients' survival were ignored.

In conclusion, our meta-analysis suggested that PVT1 could sever as a molecular biomarker to predict the clinicopathological characteristics and prognoses for tumour patients. Specifically, high PVT1 expression indicates an increased risk of metastasis and poor survival. The function and mechanism of circPVT1 in tumour progression requires further study. Importantly, PVT1 acts as ceRNA or directly binds to miRNAs in the tumourigenesis and development.

\section{ACKNOWLEDGEMENTS}

Data design, collection, analysis, and manuscript drafting: Meizhu Xiao (XMZ); data collection: Ying Feng, (FY); data analysis: Chongdong Liu (LCD); study design, data analysis, and manuscript revising: Zhenyu Zhang (ZZY); financial support: this work was supported by start-up funds from Ministry of Science and Technology of China (2017YFC1001204; 2012DFA30490). 


\section{COMPETING INTERESTS}

The authors have declared that no competing interest exists.

\section{ORCID}

Zhenyu Zhang iD http://orcid.org/0000-0002-2849-0246

\section{REFERENCES}

1. Lindsey AT, Freddie B, Rebecca LS, et al. Global cancer statistics, 2012. CA Cancer J Clin. 2015;65:87-108.

2. Ponting $\mathrm{CP}$, Oliver PL, Reik W. Evolution and functions of long noncoding RNAs. Cell. 2009;136(4):629-641.

3. Melissari MT, Grote P. Roles for long non-coding RNAs in physiology and disease. Pflugers Arch. 2016;468:945-958.

4. Weidle UH, Birzele F, Kollmorgen G, Ruger R. Long non-coding RNAs and their role in metastasis. Cancer Genomics Proteomics. 2017;14:143-160.

5. Huang T, Liu HW, Chen JQ, et al. The long noncoding RNA PVT1 functions as a competing endogenous RNA by sponging miR-186 in gastric cancer. Biomed Pharmacother. 2017;88:302-308.

6. Huang TH, Wang GS, Yang L, et al. Transcription factor YY1 modulates lung cancer progression by activating IncRNA-PVT1. DNA Cell Biol. 2017;36(11):947-958.

7. Li YF, Li SH, Luo YT, Liu Y, Yu NH. LncRNA PVT1 regulates chondrocyte apoptosis in osteoarthritis by acting as a sponge for miR-488-3p. DNA Cell Biol. 2017;36(7):571-580.

8. Zhang $\mathrm{X}, \mathrm{Bu} \mathrm{P}$, Liu L, Zhang $\mathrm{XZ}$, Li J. Overexpression of long non-coding RNA PVT1 in gastric cancer cells promotes the development of multidrug resistance. Biochem Biophys Res Comm. 2015;462:227-232.

9. Webb E, Adams JM, Cory S. Variant $(6 ; 15)$ translocation in a murine plasmacytoma occurs near an immunoglobulin $\mathrm{k}$ gene but far from the myc oncogene. Nature. 1984;312(5996):777-779.

10. Tseng YY, Moriarity BS, Gong W, et al. Pvt1 dependence in cancer with myc copy-number increase. Nature. 2014;512:82-86.

11. Brooksbank C, Bergman MT, Apweiler R, Birney E, Thornton J. The European Bioinformatics Institute's data resources 2014. Nucleic Acids Res. 2014;42(1):D18-D25.

12. Huppi K, Volfovsky N, Runfola T, et al. The identification of microRNAs in a genomically unstable region of human chromosome8q24 Mol Cancer Res. 2008;6(2):212-221.

13. Kong R, Zhang EB, Yin DD, et al. Long noncoding RNA PVT1 indicates a poor prognosis of gastric cancer and promotes cell proliferation through epigenetically regulating p15 and p16. Mol Cancer. 2015;14:82.

14. Yuan CL, Li H, Zhu L, Liu Z, Zhou J, Shu Y. Aberrant expression of long noncoding RNA PVT1 and its diagnostic and prognostic significance in patients with gastric cancer. Neoplasma. 2016;63:3.

15. Chen J, Li Y, Zheng QP, et al. Circular RNA profile identifies circPVT1 as a proliferative factor and prognostic marker in gastric cancer. Cancer Lett. 2017;388:208-219.

16. Li T, Meng XL, Yang WQ. Long noncoding RNA PVT1 acts as a 'sponge' to inhibit microRNA-152 in gastric cancer cells. Dig Dis Sci. 2017;62:3021-3028.

17. Cui D, Yu CH, Liu M, Xia QQ, Zhang YF, Jiang WL. Long non-coding RNA PVT1 as a novel biomarker for diagnosis and prognosis of non-small cell lung cancer. Tumor Biol. 2016;37:4127-4134https:// doi.org/10.1007/s13277-015-4261-x.

18. Huang CS, Liu SG, Wang HJ, et al. LncRNA PVT1 overexpression is a poor prognostic biomarker and regulates migration and invasion in small cell lung cancer. Am J Transl Res. 2016;8(11):5025-5034.
19. Wan L, Sun M, Liu GJ, et al. Long noncoding RNA PVT1 promotes non-small cell lung cancer cell proliferation through epigenetically regulating LATS2 expression. Mol Cancer Ther. 2016;15(5):1082-1094

20. Yang YR, Zang SZ, Zhong CL, et al. Increased expression of the IncRNA PVT1 promotes tumorigenesis in non-small cell lung cancer. Int J Clin Exp Pathol. 2014;7(10):6929-6935.

21. Li HL, Chen SX, Liu J, et al. Long non-coding RNA PVT1-5 promotes cell proliferation by regulating miR-126/SLC7A5 axis in lung cancer. Biochem Biophys Res Comm. 2018;495:2350-2355.

22. Guo D, Wang YL, Ren KW, Han XW. Knockdown of LncRNA PVT1 inhibits tumorigenesis in non-small-cell lung cancer by regulating miR-497 expression. Exp Cell Res. 2018;362(1):172-179.

23. Li Q, Dai Y, Wang F, Hou S. Differentially expressed long non-coding RNAs and the prognostic potential in colorectal cancer. Neoplasma. 2016:63:6.

24. Li PD, Hu JL, Ma C, et al. Upregulation of the long non-coding RNA PVT1 promotes esophageal squamous cell carcinoma progression by acting as a molecular sponge of miR-203 and LASP1. Oncotarget. 2017;8(21):34164-34176.

25. Wu BQ, Jiang $\mathrm{Y}$, Zhu $\mathrm{F}$, et al. Long noncoding RNA PVT1 promotes EMT and cell proliferation and migration through downregulating p21 in pancreatic cancer cells. Technol Cancer Res Treat. 2016;16:819-827.

26. Zhao L, Kong HR, Sun HW, Chen ZJ, Chen BC, Zhou MT. LncRNAPVT1 promotes pancreatic cancer cells proliferation and migration through acting as a molecular sponge to regulate miR-448. J Cell Physiol. 2017;13:295-307.

27. Huang $C$, Yu W, Wang Q, et al. Increased expression of the IncRNA PVT1 is associated with poor prognosis in pancreatic cancer patients. Minerva Med. 2015;106:143-149.

28. Gou X, Zhao XY, Wang ZR. Long noncoding RNA PVT1 promotes hepatocellular carcinoma progression through regulating miR-214. Cancer Biomarkers. 2017;20:511-519.

29. Lan T, Yan X, Li Z, et al. Long non-coding RNA PVT1 serves as a competing endogenous RNA for miR-186-5p to promote the tumorigenesis and metastasis of hepatocellular carcinoma. Tumor Biol. 2017;39:1-11.

30. Wang F, Yuan JH, Wang SB, et al. Oncofetal long noncoding RNA PVT1 promotes proliferation and stem cell-like property of hepatocellular carcinoma cells by stabilizing NOP2. Hepatology. 2014;60:1278-1290.

31. Wang Y, Zhou J, Wang ZX, Wang PS, Li SQ. Upregulation of SOX2 activated LncRNA PVT1 expression promotes breast cancer cell growth and invasion. Biochem Biophys Res Comm. 2017;493:429-436.

32. Shen CJ, Cheng YM, Wang CL. LncRNA PVT1 epigenetically silences miR-195 and modulates EMT and chemoresistance in cervical cancer cells. J Drug Target. 2017;25(7):637-644.

33. Zhang SR, Zhang GL, Liu JY. Long noncoding RNA PVT1 promotes cervical cancer progression through epigenetically silencing miR-200b. APMIS. 2016;124:649-658.

34. Verduci L, Ferraiuolo M, Sacconi A, et al. The oncogenic role of circPVT1 in head and neck squamous cell carcinoma is mediated through the mutant p53/YAP/TEAD transcription-competent complex. Genome Biol. 2017;18:237.

35. Martini P, Paracchini L, Caratti GL, et al. IncRNAs as novel indicators of patients' prognosis in stage i epithelial ovarian cancer: a retrospective and multicentric study. Clin Cancer Res. 2016;23(9):2356-2366.

36. Zhou Q, Chen FL, Zhao JL, et al. Long non-coding RNA PVT1 promotes osteosarcoma development by acting as a molecular sponge to regulate miR-195. Oncotarget. 2016;7:82620-82633.

37. Wang BJ, Ding HW, Ma GA. Long noncoding RNA PVT1 promotes melanoma progression via endogenous sponging MiR-26b. 
Oncol Res. 2017;26:675-681. https://doi.org/10.3727/0965040 $17 X 14920318811730$.

38. Song JY, Wu XL, Liu FX, et al. Long non-coding RNA PVT1 promotes glycolysis and tumor progression by regulating miR-497/HK2 axis in osteosarcoma. Biochem Biophys Res Comm. 2017;490:217-224.

39. Dong YP, He D, Peng ZZ, et al. Circular RNAs in cancer: an emerging key player. J Hematol Oncol. 2017;10:2.

40. Memczak S, Jens M, Elefsinioti A, et al. Circular RNAs are a large class of animal RNAs with regulatory potency. Nature. 2013;495:333-338.

41. Li P, Chen S, Chen $\mathrm{H}$, et al. Using circular RNA as a novel type of biomarker in the screening of gastric cancer. Clin Chim Acta. 2015;444:132-136.

42. Wang $X$, Zhang $Y$, Huang $L$, et al. Decreased expression of hsa_ circ_001988 in colorectal cancer and its clinical significances. Int J Clin Exp Pathol. 2015;8:16020-16025.

43. Huang G, Zhu H, Shi Y, et al. Cir-ITCH plays an inhibitory role in colorectal cancer by regulating the Wnt/ $\beta$-catenin pathway. PLoS ONE. 2015;10:e131225.

44. Labbate A, Tolomeo D, Cifola I, et al. MYC-containing amplicons in acute myeloid leukemia: Genomic structures, evolution, and transcriptional consequences. Leukemia. 2018. https://doi.org/10.1038/ s41375-018-0177-y.

45. Altman DG, McShane LM, Sauerbrei W, Taube SE. Reporting recommendations for tumor marker prognostic studies (REMARK): explanation and elaboration. BMC Med. 2012a;10:51.

46. McShane LM, Altman DG, Sauerbrei W, Taube SE, Gion M, Clark GM; Statistics Subcommittee of the NCIEWGoCD. REporting recommendations for tumour MARKer prognostic studies (REMARK). Br J Cancer. 2005;93(4):387-391.

47. DerSimonian R, Laird N. Meta-analysis in clinical trials. Control Clin Trials. 1986;7(3):177-188.

48. Cohen J. A coefficient of agreement for nominal scales. Educ Psychol Meas. 1960;20(1):37-46.

49. Xu M-D, Wang $Y$, Weng $W$, et al. A positive feedback loop of IncRNA-PVT1 and FOXM1 facilitates gastric cancer growth and invasion. Clin Cancer Res. 2016;23(8):2071-2080.

50. Takahash Y, Sawada G, Kurashige J, et al. Amplification of PVT-1 is involved in poor prognosis via apoptosis inhibition in colorectal cancers. Br J Cancer. 2014;110:164-171.

51. Yang T, Zhou H, Liu PJ, et al. IncRNA PVT1 and its splicing variant function as competing endogenous RNA to regulate clear cell renal cell carcinoma progression. Oncotarget. 2017;8(49):85353-85367.

52. Tian X, Xu G. Clinical value of IncRNA MALAT1 as a prognostic marker in human cancer: systematic review and meta-analysis. BMJ Open. 2015;5(9):e008653.

53. Cory S, Graham M, Webb E, Corcoran L, Adams JM. Variant(6;15) translocations in murine plasmacytomas involve a chromosome 15 locus at least $72 \mathrm{~kb}$ from the c-myc oncogene. EMBO J. 1985;4(3):675-681.

54. Graham M, Adams JM. Chromosome 8 breakpoint far 3' of the c-myc oncogene in a Burkitt's lymphoma 2;8 variant translocation is equivalent to the murine pvt-1 locus. EMBO J. 1986;5(11):2845-2851.

55. Orman S, Cayci HM. Gastric cancer: factors affecting survival. Acta Chir Belg. 2018;21:1-7.
56. Wang L, Liu Z, Liu X, Zeng Y, Liu J. The hepatectomy efficacy of huge hepatocellular carcinoma and its risk factors: a meta analysis. Medicine (Baltimore). 2017;96(52):e9226.

57. Colombo T, Farina L, Macino G, Paci P. PVT1: a rising star among oncogenic long noncoding RNAs. Biomed Res Int. 2015;2015:304208.

58. Paci P, Colombo T, Farina L. Computational analysis identifies a sponge interaction network between long non-coding RNAs and messenger RNAs in human breast cancer. BMC Syst Biol. 2014;8:83.

59. Chen W, Zhu HY, Yin L, et al. IncRNA-PVT1 facilitates invasion through upregulation of MMP9 in nonsmall cell lung cancer cell. DNA Cell Biol. 2017;36(9):787-793.

60. Wu DP, Li Y, Zhang HX, Hu XG. Knockdown of Lncrna PVT1 enhances radiosensitivity in non-small cell lung cancer by sponging Mir-195. Cell Physiol Biochem. 2017;42:2453-2466.

61. Welsh SJ, Powis G. Hypoxia inducible factor as a cancer drug target. Curr Cancer Drug Targets. 2003;3(6):391-405.

62. Wang C, Han C, Zhang Y, Liu F. LncRNA PVT1 regulate expression of HIF1-a via functioning as ceRNA for miR-199a-5p in non-small cell lung cancer under hypoxia. Mol Med Rep. 2018;17(1):1105-1110.

63. Gao YL, Zhao ZS, Zhang MY, Han LJ, Dong YJ, Xu B. Long noncoding RNA PVT1 facilitates cervical cancer progression via negative regulating of miR-424. Oncol Res. 2017;25:1391-1398.

64. Liu HT, Fang L, Cheng YX, Sun Q. LncRNA PVT1 regulates prostate cancer cell growth by inducing the methylation of miR-146a. Cancer Med. 2016;5(12):3512-3519.

65. Ma YW, Wang P, Xue YX, et al. PVT1 affects growth of glioma microvascular endothelial cells by negatively regulating miR-186. Tumour Biol. 2017;39(3):1010428317694326.

66. Nigro JM, Cho KR, Fearon ER. Scrambled exons. Cell. 1991;64:607-613.

67. Panda AC, Grammatikakis I, Kim KM, et al. Identification of senescence-associated circular RNAs (SAC-RNAs) reveals senescence suppressor CircPVT1. Nucleic Acids Res. 2017;45:4021-4035.

68. Jeck WR, Sorrentino JA, Wang K, et al. Circular RNAs are abundant, conserved, and associated with ALU repeats. RNA. 2013;19:141-157.

69. Memczak S, Papavasileiou P, Peters $\mathrm{O}$, et al. Identification and characterization of circular RNAs as a new class of putative biomarkers in human blood. PLoS ONE. 2015;10:e0141214.

\section{SUPPORTING INFORMATION}

Additional supporting information may be found online in the Supporting Information section at the end of the article.

How to cite this article: Xiao M, Feng Y, Liu C, Zhang Z. Prognostic values of long noncoding RNA PVT1 in various carcinomas: An updated systematic review and meta-analysis. Cell Prolif. 2018;51:e12519. https://doi.org/10.1111/cpr.12519 